\title{
Governing the Globalization of Public Health
}

\author{
Allyn L. Taylor
}

$\mathrm{T}$ he number and the scale of transboundary public health concerns are increasing. Infectious and non-communicable diseases, international trade in tobacco, alcohol, and other dangerous products as well as the control of the safety of health services, pharmaceuticals, and food are merely a few examples of contemporary transnationalization of health concerns. The rapid development and diffusion of scientific and technological developments across national borders are creating new reaims of international health concern, such as aspects of biomedical science, including human reproductive cloning, germ-line therapy, and xenotransplantation, as well as environmental health probiems, including climate change, biodiversity loss, and depletion of the ozone layer. Growth in international trade and travel, in combination with population growth, has served to increase the frequency and intensity of health concerns bypassing or spilling over sovereign boundaries.

Although health has traditionally been seen an area of limited multilateral cooperation, there is growing awareness that contemporary globalization has led to the proliferation of cross border determinants of health status and is undermining the capacity of nation states to protect health through domestic action alone. Consequently, globalization is creating a heightened need for new global health governance structures to promote coordinated intergovernmental action.

This emerging need for new mechanisms and models for collective health action is a fundamental force behind the rapid expansion of international health law. Today, the growing field of international health law encompasses treaties and other legal instruments addressing diverse and complex concerns and is increasingly recognized as integrally linked to most other traditionally defined international legal realms.

Despite growing awareness of the capacity of conventional international law to serve as a dynamic tool for multilateral health cooperation in an increasingly interdependent world, little scholarly consideration has been paid to how twenty-first century giobal health - lawmaking should be managed from an international institutional basis. ${ }^{1}$ With multiple international organizations sharing lawmaking authority for global health and with other actors engaged in the international legislative process, international lawmaking shows potential for fragmented, uncoordinated, and inefficient sprawl.

This article seeks to contribute to the emerging discussion on global health governance by examining how globalization and the rising need for new global health governance structures is a driving force behind the expansion of conventional international health law. The article considers the complexities associated with using conventional vehicles to advance international cooperation and the inherent limitations of the international legislative process. It examines whether the present institutional framework is adequate and appropriate to meet the emerging global health law governance needs of the world community and whether leadership by the World Health Organization could strengthen global coordination and effective implementation of future developments in this rapidly evolving domain of international legal concern. Conventional international law is the primary intemational legal vehicle by which international organizations can advance international legal cooperation, so the article focuses on treaty law rather than other sources of international law.

\section{The Evolution of International Law}

Related to Public Health

Globalization and the Expanding Domain

of International Health Law

It has been widely observed that globalization has criticai implications for public health and global public health governance. ${ }^{2} \mathrm{~A}$ dominant characteristic of contemporary globalization is that it has introduced or expanded risks to health that transcend national borders in their origin or impact. ${ }^{3}$ Such risks may include emerging and re-emerging infectious diseases, global environmental degradation, food safety; and an array of non-communicable diseases as well as trade in harmful commodities such as tobacco.

For example, the magnitude of the global impact of catastrophic appearances of new infectious diseases and the violent worldwide reemergence of oid contagions has vividly evidenced the globalization of public health. Over the last two decades nations worldwide have been confronted with outbreaks of virulent strains of many old diseases and over thirty newly recognized pathogens, inciuding, most notably, HIV/AIDS. Most recently, the well-publicized global threats of severe acute respiratory syndrome (SARS) in late 2002 and 2003 and outbreaks of both human ( $\mathrm{H} 3 \mathrm{~N}_{2}$ ) and avian ( $\mathrm{H} 5 \mathrm{N1}$ ) influenza less than a year later captured public and media attention. The SARS epidemic spread rapidly from its origins in southern China until it had reached more than 25 other countries within a matter of months. In addition to the number of patients infected with the SARS virus, totaling more than 8000 cases and 774 known deaths, the disease had

Allyn L. Taylor, JD, LLM, JSD, is currently Adjunct Professor in Residence at the University of Maryland School of Lave. From 1998 to 2003 she was a Senior Health Policy Adviser at the World Health Organization, Geneva. 
profound economic and political repercussions in many of the affected regions. Reports in early 2004 of isolated new SARS cases and a fear that the disease could reemerge and spread put public health officials on high alert for any indications of possible new outbreaks. Concerns about rapid world wide transmission of communicable diseases were confounded by epidemic outbreaks of both human (H3N2) and avian (H5N1) influenza in 2003-2004. Although these two recent epidemics have thus far had a limited relative impact on global health, the magnified public attention has promoted a mobilizing vision for coordinated health action and, in some cases, jolted global awareness and appreciation of the interconnectedness between domestic and international health.

The impact of increasing global integration for the globalization of public health is not, of course, an entirely new phenomenon. It has long been recognized that challenges to health are increasingly internationa $]^{4}$ and have led to the obsolescence of the traditional distinction between national and international heal th policy. ${ }^{5}$ However, contemporary globalization has had an unprecedented impact on global public health.

As Dodgson, Lee, and Drager have observed, the dramatic growth in geographical scope and speed with which contemporary transborder health risks have emerged has effectively challenged the established system of health governance defined by national boundaries. ${ }^{6}$ Contemporary globalization has thus contributed to the rapid decline in the practical capacity of sovereign states to address contemporary health challenges through unilateral action alone and has amplified the need for health governance that transcends traditional and increasingly inadequate unilateral national approaches.

Conventional international law - treaty law - has received new prominence as a tool for multilateral cooperation in the public health field as states increasingly recognize the need to complement domestic action in the health sector with cross-sector and cross-border action to protect the health of their populations. The momentum of globalization is such that governments must turn increasingly to international cooperation to attain national public health objectives. Globalization has increased the need for new, formalized frameworks of international collaboration, including conventional international law, to address emerging global health threats and to improve the health status of poor states that have not benefited from globalization - the so-called "losers" of globalization. ${ }^{7}$ Global health governance is, therefore, not about one world government, but about institutions and legal practices that facilitate multilateral cooperation among sovereign nation states. ${ }^{8}$

Globalization has also impacted the development of international health law, because increasing global integration has compounded the impact of other contemporary global developments that are strongly connected with health status and thereby magnified the need for frameworks for international cooperation. For example, the spread of communication and information technologies has dramatically accelerated the rate of scientific progress and its diffusion and application around the globe. This rapid worldwide dissemination of recent advances in scientific knowledge and technology has advanced international agreement and action by providing the evidence base and the technological tools needed for effective national action and international cooperation in a wide range of treaties - including those concerned with the safety of chemicals, pesticides, and food and the disposal of hazardous wastes. At the same time, however, the use of environmentally damaging technologies has also contributed to the codification of international law by propelling global health threats such as biodiversity loss, marine pollution, depletion of the ozone layer, and climate change. Further, continuing scientific progress and developments are generating ongoing global debate on codifying new international commitments, including global bans on certain novel technologies, such as reproductive human cloning. ${ }^{9}$

\section{Issue Linkage}

Globalization has contributed to the expansion of international health by contributing to enhanced appreciation of the interconnectedness of contemporary global concerns and, concomitantly, the "linkage" of health to other international legal issues. International legal scholars have conventionally compartmentalized and treated substantive subject matters such as human rights, environmental protection, heaith and arms control, as discrete, self-contained areas with limited connections. ${ }^{10}$ Students of international law have only recently begun to recognize the nexus among different realms of international law, such as trade and human rights, and human rights and environmental protection. ${ }^{\text {" }}$

The evolution of the concept of international security, a realm at the fore of the global community's political agenda, provides an interesting example of this phenomenon. The traditional understanding of international security has come under increasing scrutiny in recent years with growing support for a comprehensive and multisectoral conceptualization of security that addresses the wide-ranging factors that impact on the vulnerability of people. The linkage between health and security sits squarely at the center of this movement. For instance, in May 2003, the Commission on Human Security released a report proposing a new security framework that focuses directly on improving the human condition. including a key public health component. ${ }^{12}$

As a further example, the development agenda has evolved over the past few years from a view focused exclusively on anbridled and "trickle-down" economic growth, towards a more holistic perspective that economic growth should be cased by multidimensional concepts such as sustainable development and human development. The concepts of human development and sustainable development encompass the idea of expanded intersectoral action and coordination of economic, social, and environmental policy to improve the human condition. Health and the relationship between improved health and development are at the core of this development agenda ${ }^{13}$ At the same time as these developments public health policy-makers have expanded intersectoral global public health action to address the increasingly evident intersectoral determinants of health status, including poverty, education, technology, and the environment.

These global public policy developments have important implications for the conceptualization and advancement of international health law. ${ }^{14}$ As a consequence of "issue linkage" international health law is increasingly understood to be a key component of other international legal regimes, including labor law, human rights, environmental law, trade, and arms control. For example, the extraordinary growth of international trade means the link between health and trade in a number of the World Trade Organization (WTO)'s treaties is becoming increasingly manifest in a wide range of areas including access to medicines, food security, nutrition, infectious disease control, and biotechnology. ${ }^{15}$ In addition, as noted above, health has been linked to international peace and security issues in multiple contexts, including those of HIV/AIDS, and biological and other weapon systems. Overall, health is emerging as a central issue of multilateralism as a consequence of issue linkage in combination with the widespread impact of globalization.

"Issue linkage" is not limited to mere doctrinal debates, but also im- 
pacts contemporary codification efforts. Coordinated action on health and other traditionally distinct substantive concerns has become increasingly commonplace in international legislative projects. For example, as described above, sustainable development encompasses the idea of intersectoral coordination of environmental, economic, and social policy to improve the human condition. ${ }^{16}$ The praxis of sustainable development informed the 1992 Rio Declaration on Environment and Development and has been elaborated in a number of international instruments, including the Conventions on Climate Change and Biological Diversity.

As a further example, the evolution of international health law has been very much tied to the protection and promotion of human rights related to physical and mental integrity. ${ }^{17}$ The principal international legal basis for the right to health and other human rights relevant to health is found in the core instruments of human rights law: the International Bill of Rights which consists of the Universal Declaration of Human Rights (1948), the International Covenant on Economic, Social and Cultural Rights (1966), and the International Covenant on Civil and Political Rights (1966). However, there has been an emerging global understanding, arising primarily from public health approaches to HIV/AIDS, that human rights and public health are intertwined and interdependent. ${ }^{18}$ Consequently, the domain of human rights in relation to health has expanded conspicuously in the last decade or so with bodies of the United Nations system paying increasing attention to the interrelation between health and human rights, and tailored human rights instruments now address the rights of particular populations, such as persons with HIV/AIDS and disabilities, women, children, migrant workers, and refugees ${ }^{19}$ and, most recently, the interrelation between the human right to health and access to medicines.

\section{The Promise and Limitations of International Law for Global health Governance}

Health has emerged as a key global policy issue as a consequence of the globalization of public health, including the recently enhanced appreciation of the centrality of health to most reaims of international relations.

Contemporary international health law includes a wide and growing diversity of international concerns. The scope and depth of contemporary international health law and its nexus with other realms of international legal concern reflects growing multilateral concern with and international cooperation to address the impact of contemporary globalization on public health, including aspects of biomedical science, human reproduction and cloning, organ transplantation and xenotransplantation, infectious and non-communicable diseases, intemational trade and the control of safety of health services, food and pharmaceuticals, and the control of addictive substances such as tobacco and narcotics. ${ }^{20}$ As described above, international health law is also increasingly linked with other realms of multilateral concern. Arms control and the banning of weapons of mass destruction, international human rights and disabilities, international labour law and occupational health and safety, environmental law and the control of toxic pollutants, nuclear safety and radiation protection, and fertility and population growth are all intimately related to the domain of international health law. ${ }^{21}$ The current configuration of international health law and the contribution of intergovernmental organizations to its development have recently been examined. ${ }^{22}$

Globalization is creating new and increasingly difficult governance needs. In the realm of public health, enhanced cooperation among nation states is proving increasingly necessary to address the rising number and complexity of transboundary health problems. Global health governance in the twenty-first century, therefore, is likely to include expanded use of international law through the codification of new agreements and the adaptation of existing ones as nations at all levels of development increasingly recognize the need to provide a framework for coordinated action in an increasingly interdependent world. Global health development strategies, including the codification and implementation of treaty law, will be needed to address increasingly complex, intersectoral, and interrelated global health problems.

The burgeoning literature examining health and international health law as global public goods testifies to the increasing signifcance of conventional international law as a mechanism for future international collective action in this era of globalization. ${ }^{23}$ The interdependence and integration associated with globalization means that providing global public goods such as public health increasingly requires action to be undertaken at the global level through effective international cooperation.

Notably, the ever-expanding sense of global heaith interdependence and global health vulnerability fostered by contemporary globalization may also, over time, become a powerful factor in overcoming the penchant for isolationism or unilateralism that, at times, has characterized the foreign policy of some powerful states, including, most notably, the United States, and thus contribute to the relevance of international health law by encouraging both the codification and implementation of effective international commitments.

Conventional international law is, of course, an inherently imperfect mechanism for international cooperation and the international legislative process is characterized by numerous and manifest limitations - including challenges to timely commitment and implementation - although considerable advances have been made in the last few decades. ${ }^{24}$

Globalization has also, in some respects, magnified the complexity of using conventional international law as an effective vehicle for intergovernmental cooperation. Increasing global interdependence may, as suggested above, enhance the codification and implementation of effective international health commitments by expanding awareness of global health vulnerability and the need for collective and concerted action. However, while contemporary health challenges are of concem to all countries because of their transborder character, many such problems are particularly acute in the poorest nations that are in the weakest position to negotiate effective and collective international obligations. Further, the deepening of poverty and accentuation of health inequalities among and within countries as well as the expanding numbers of increasingly complex and multifarious transnational health concerns and determinants of health status considerably compounds the challenge of using international legislation as a means to promote global public goods. In addition, as described further herein, the expansion in the number and power of non-state actors in the health domain is impacting on the capacity of traditional modes of state- to- state cooperation, including international law, to address global health concerns.

Despite the conspicuous limitations of the international lawmaking process and the inherent challenges associated with using treaties to promote international collective action in a globalizing world, treaties can be useful for raising public awareness and stimulating international commitment and national action. As an increasing number of health threats are global in scope or have the potential to become so, international treaties and other such legal mechanisms are of vital and ever-increasing importance and are an essential, albeit limited, component of future global health governance.

\section{Global Health Governance and International Law: The Institutional Framework Contemporary Global Health Governance}

In recent years there has been considerable development in the field of international organization with the number of intergovernmental organizations active in the domain of health and other fields of international relations growing dramatically. A diversity of intergovernmental organizations now contribute to the elaboration of the 
increasingly complex and multivaried field of international health law. ${ }^{25}$ These include the United Nations and its agencies, organs, and other bodies, and international and regional organizations outside of the United Nation's system. Within the comprehensive United Nations-system, for example, organizations with significant involvement in the health sector include WHO, UNICEF, FAO, UNEP, UNDP, UNFPA and The World Bank. Globalization has also expanded the web of relevant international organizations in the field of global health, including, notably, the WTO. Overall, an increasing number of intergovernmental organizations with express lawmaking authority and relevant mandates have served as platforms for the codification of international law related to health; others have influenced contemporary international law in this field.

More than fifty years after the founding of the United Nations, the world has changed dramatically and there has been a multiplication of non-state actors in international health with the private sector becoming an increasingly important player in health governance. These non-state actors include a wide assortment of foundations, religious groups, nongovernmental agencies and for-profit organizations such as the pharmaceutical industry - with a powerful influence on international health policy, including global lawmaking. Innovative "international health coalitions" that involve diverse global health actors, ${ }^{26}$ such as health research networks and public-private partnerships are also increasingly commonplace and have an important influence on contemporary global health governance. ${ }^{27}$

The growing significance of non-state actors in global health governances combined with widespread criticism of the United $\mathrm{Na}$ tions and its specialized agencies, including WHO, has led some commentators to suggest a declining and, perhaps, dwindling role for intergovernmental organizations in global health governance. Further, it is argued that giobalization is not only reducing the capacity of national governments to address health challenges alone, but also, by extension, collectively through intergovernmental institutions. ${ }^{28}$ The rise of innovative health coalitions, which often incorporate international organizations, is considered as a particular challenge to the continued authority of international organizations. Some commentators have emphasized a gradual reallocation of power from intergovernmental organizations to private-sector actors and the innovative health coalitions. which have gained increasing power and influence in giobal health governance. ${ }^{29}$ According to this view, the overall growth in the number and degree of influence in nonstate actors in health governance has led to blurring of the distinct roles of state and non-state actors in governance activities such as resource mobilization ${ }^{30}$ and contributed to a reallocation of authority and, perhaps, legitimacy in health governance.

Although globalization has facilitated the rise and influence of new non-state actors in health, increasing global health interdependence in fact requires that multilateral organizations play a larger role in international health cooperation ${ }^{31}$ - at least in the emerging realm of international health lawmaking and implementation. As this article has illustrated, contemporary globalization has brought about profound changes in the international context creating a greater need for meaningful intergovernmental coordination than ever before. At the same time, it is widely recognized that globalization has tended to weaken, diminish, and even fragment the state, but it has not crushed, destroyed, or replaced it. Ultimately, states retain the final authority and responsibility to decide which issues are considered and negotiated at the international level and implemented into domestic law and policy. Hence, while the growing influence of new health actors may have led to the biurring of traditional roles in some aspects of international health, this is not the case for international health lawmaking.

The vast majority of international legislative projects are con- . ducted under the auspices of international organizations. Public in- " ternational organizations are institutional mechanisms for multilaterai cooperation and collective action. Their organizational structures and formal administrative arrangements provide stable negotiating forums for member states in realms within their relevant legal authority, thereby anchoring and facilitating intergovernmental cooperation. ${ }^{32}$ Private-sector actors cannot replace international organizations as institutional focal points for global debate and codification of binding norms by state actors. Consequently, as this article has illustrated, public international organizations with relevant lawmaking authority will provide increasingly important vehicles through which states can develop and implement public policy as global integration progresses.

\section{Institutional Overload}

The proliferation and patchwork development of multilateral organizations with overlapping ambitions and legal authority creates the risk that international health law may develop in an inconsistent and suboptimal manner. The experience of international environmental law over the last twenty years provides a cautionary example that demonstrates that uncoordinated lawmaking activity by different intergovernmental organizations may have counterproductive and inconsistent results. ${ }^{33}$ Scholars argue that, as a consequence of the absence of an umbrella environmental agency, global environmental governance has suffered from "institutional overload." ${ }^{\text {"34 }}$ That is, the plethora of treaties and organizations relating to the environment has exceeded the capacity of states to effectively participate in and comply with them. The inefficient management of global environmental lawmaking has, in part, led some commentators to identify the need for the establishment of a new public international organization - the "World Environment Organization." 35

There is significant risk that a similar condition of "institutional overload" and inconsistent standard-setting will emerge in international health, a development which will detract from efforts to address the important global risks to health and to manage the new technologies with great potential to advance global public health. For example, dramatic advances in the field of biomedical science - a realm with vast opportunities and risks to global public health - has recently triggered numerous, uncoordinated regional and global initiatives, ${ }^{36}$ which have considerably complexified rather than rationalized the global legal framework.

At the global level, UNESCO, WHO, the United Nations Commission for Human Rights, UNEP and the WTO have all contributed to the elaboration of international instruments in this rapidly evolving field without any meaningful institutional consultation, coordination or planning. The first international instrument to address a broad range of human rights and public health implications of biotechnology, the Universal Declaration on the Human Genome and Human Rights was adopted by the UNESCO General Conference in 1997. More recently, in 2003, UNESCO adopted an International Declaration on Human Genetic Data and, at the time of this writing, is in the process of preparing to negotiate a new proposed Declaration on Universal Norms on Bioethics. During this same period of time, the United Nations Commission for Human Rights has adopted resolutions pertaining to human rights and bioethics with implications for public health, ${ }^{37}$ while WHO has also adopted resolutions 
and recommended standards on the social, ethical, and scientific implications of biotechnology, including human reproductive cloning.

There is growing evidence of fragmentation, duplication, and inconsistency in this highly complex realm, particularly with respect to binding instruments that have been adopted under the auspices of the assorted international organizations involved in the field. For example, some of the aspects of the biotechnology revolution for biodiversity are addressed in the United Nations Environment Programmes Convention on Biological Diversity and Biosafety Protocol. At the same time, the WTO's Convention on Trade-related Aspects of Intellectual Property establishes standards for protection of intellectual property applicable to biotechnology and severai other WTO agreements also apply to biotechnology-related trade disputes. Most recently, in December 2001, the United Nations General Assembly established an Ad Hoc Working Group of the Sixth Committee to consider a proposed new treaty to ban the reproductive cloning of human beings. This negotiation process has been stymied by a split between those states, led by the United States, that favor a broadbased cloning treaty that bans all human cloning, including therapeutic cloning, and those states that favor a treaty with a narrow focus on human reproductive cloning. In the absence of consensus on the scope of the proposed instrument, in late 2003, the United Nations Member States agreed to postpone discussions of the proposed treaty until late $2004 .^{38}$ Notably, no consideration has been given to extending the scope of the treaty to comprehensively address critical and timely issues in species, altering technology, such as germ line therapy. ${ }^{39}$

These examples illustrate that international law in biotechnology is developing in a splintered and disconnected manner as intergovernmental organizations with overlapping claims to legal jurisdiction are addressing isolated aspects of the genetics revolution in a piecemeal and incomplete manner. ${ }^{40}$ Instead of fostering effective interagency coordination and strengthened multilateral cooperation to harness the genetics revolution to advance global public health, the splintered legal process is aggravating uncertainty about the legal regime that governs biotechnology. This is partly because standards adopted under the auspices of different international organizations are being developed in increasingly contradictory ways, including conflicting legal standards related to intellectual property. ${ }^{41}$

This suggests that, similar to the experience of international environmental law, the multiplicity of public international organizations engaged in standard-setting in biotechnoiogy is also likely to lead to "treaty congestion" and overwhelm the capacity of states to participate in the lawmaking enterprise and to implement international commitments. In some respects "institutional overload" in biotechnology appears to be leading to a situation of normative overkill. At the same time, the emerging patchwork of international law in biotechnology may still fail to comprehensively address the most important implications of the genetics field for human health. Despite the extensive international legislative activity in this area, there is no legally binding global instrument even under consideration that addresses the considerable public health implications of the globalization of biotechnology.

\section{Advancing Global Health Law Governance}

An International Health Law Mandate for WHO

Lessons from the experience of the last several decades of global environmental governance and recent codification efforts in biotechnology illustrate that the international health law enterprise necessitates more effective collective management. More effective institutional coordination than exists in the current decentralized or- national organizations. ${ }^{42}$

ganizational framework is also needed because the phenomenon of "issue linkage" in contemporary lawmaking confounds the conundrum of contradictory international health law rules developed under the auspices of different organizations with overlapping legal authority. In international law generally, the question of issue linkage is increasingly understood to concern the allocation of legal jurisdiction among inter-

The World Health Organization bas a unique directive to provide leadership and promote rational and effective development of the evolving field of international health law. As the largest international health organization, WHO has wide-ranging responsibilities to address global public health concerns based on responsibilities assigned by its constitution and its affiliation with the Linited Nations. ${ }^{43}$

The structure of the relationship between the United Nations and WHO is grounded in the United Nations Charter and, in particular, those sections that describe the objectives of the United Nations. Article 5.5 of the Charter describes the goals that the United Nations has pledged to promote among its members, including solutions of international, economic, social, health, and related problems. As the specialized agency with the primary constitutional directive to act as the "directing and co-ordinating authority" on international health work, WHO has the cardinal responsibility to implement the aims of the Charter with respect to health. Although the broad idea that WHO should promote coordination throughout the United Nations system is not new to global health governance literature. it deserves more serious consideration in this neglected realm of international health lawmaking because of the implications of the current leadership vacuum.

System-wide coordination does not mean full centralization of all international health lawmaking functions under WHO's auspices. For at least six reasons, consolidation of all international health law making functions under WHO is neither feasible nor desirable. First, as described the field of international health law is growing rapidly encompassing more diverse and complex concerns, in part. as a consequence of issue linkage. Although health is a component of an increasing number of such codification efforts, not all such treaty enterprises fall squarely within WHO's core mandate. Second. as described further herein, WHO currently has highly limited experience in international health lawmaking and management of global legal developments. Therefore, WHO lacks the requisite capacity to undertake full centralization of all lawmaking functions in this rapidly developing field. Third, expanding WHO's mandate to address all aspects of international health law codification could also deplete the organization's existing resources and potentially undermine the ability of the institution to fulfil its well-established and essential international health functions.

Fourth, member states are highly unlikely to limit their autonomy and freedom of action by granting WHO such broad jurisdiction or, given current economic conditions, to provide it with the vast new resources needed to implement such an expansive new mandate. Fifth, other international organizations with overlapping legal jurisdiction would undoubtedly defend against full centralization under the auspices of WHO. ${ }^{44}$ WHO has no binding authority over the activities of other autonomous intergovernmental organizations and, regrettably, competition rather than coordination has been a traditional stamp of organizational relations throughout the United Nations system.

Fifth, it is important to recognize that there are some advantageous aspects of the decentralization of the international lawmaking enterprise. In particular, as Doyle and Massey have observed, decentralization generates opportunities for international organizations to 
specialize and promotes innovation ${ }^{45}$ For example, some existing intemational organizations, such as the Food and Agriculture Organization of the United Nations, have substantial specialized technical expertise and legal experience that will make an important contribution to future lawmaking efforts. The growing complexity and interconnectedness of global health problems suggest that certain situations will require moving beyond the "single instrument and single institution" approach. ${ }^{46}$ Notably, in the realm of international environmental law, decentralization of the actual lawmaking enterprise among different institutions has been recognized as a critical factor in the regime's widely recognized dynamism. ${ }^{47}$

While all lawmaking functions should not be consolidated under WHO auspices, WHO leadership in coordinating codification and implementation efforts among the diverse global actors actively engaged in health lawmaking could, in theory, foster the development of a more effective, integrated and rational legal regime and, consequently, better collective management of global health concerns. Expectations of WHO's capacity to manage the international health law enterprise must be reasonable and pragmatic, however. It is important to recognize that effective coordination of international legal efforts cannot be guaranteed by WHO or by any other intergovernmental organization. Efficiency of international standards and consistency among different treaties may not always be a priority among states codifying international commitments or the wide array of global health actors, including other autonomous intergovernmental organizations, that influence the international legislative process. Although effective coordination of the increasingly complex international health law regime cannot be assured, an effort to rationalize the international health law enterprise should pursued with reasonable expectations and awareness of the limitations of organizational action.

\section{Organizational and Political Capacity}

A fundamental precept in global governance is that the "the mandate should fit the organization and vice versa. ${ }^{\text {"48 }}$ While WHO clearly has the legal capacity to serve as a platform for international health law coordination efforts, a key question that remains is whether or not it has the necessary organizational and political capacity to meet the complex new challenges associated with the international health law leadership mandate proposed in this article.

WHO is unique among United Nations specialized agencies in that the Organization has traditionally neglected the use of international legislative strategies to promote its global public policies. Despite wide-ranging advancements in international lawmaking by numerous intergovernmental organizations since the founding of the United Nations over fifty years ago, until recently, WHO encouraged the formulation of binding international standards in very limited and traditional contexts and never promoted the use of its constitutional authority to serve as a platform for treaty negotiations in any area of public health. A decade ago, I attributed WHO's "traditional conservatism" about the use of legal institutions largely to its cultural predispositions - its organizational culture. ${ }^{49}$

Some observers continue to marginalize the role of WHO in international law, but it is unclear whether and to what extent the conceptualization of WHO's traditional culture is still relevant. Under the leadership of Dr Gro Harlem Brundtland, Director-General of WHO from 1998-2003, there were wide-ranging changes in WHO's traditional organizational behavior. During Brundtland's tenure international law became more widely integrated into WHO's work than at any other time in the Organization's history. Among other things, the Organization initiated efforts to explore practical linkages between health and other realms of international law and develop and influence relevant global public policy. For example, some concrete efforts were made to establish a broader dialogue between WHO and the WTO in order to promote health as a legitimate concern on the global trade agenda and currently WHO holds official observer status on the
Council of the WTO and sorne of its key committees. ${ }^{50}$ As a further example, notable strides were made to address the Organization's historical neglect of the linkage between health and human rights. ${ }^{51}$ - Among other things, the Organization established its first health and human rights adviser post and sought to strengthen is role in providing technical, intellectual and political leadership in the field. ${ }^{52}$

Two international legislative projects were also effectively launched in the last five years. First, the Organization rejuvenated the process of revising and updating the International Health Regulations, potentially a key international instrument in the area of communicable disease control. Second and, perhaps, most significantly, WHO revived and accelerated the process of negotiating and adopting its first convention - the Framework Convention on Tobacco Control an idea that had been initiated in the early $1990 \mathrm{~s}^{53}$ and formally proposed in an independent feasibility study for WHO in $1995,{ }^{54}$ but had languished prior to the election of Brundtland. With a strong push from WHO in the late 1990 s, the idea of a WHO tobacco convention became a viable international negotiation process involving over 160 countries. A final draft of the Convention was adopted by the World Health Assembly, the legislative organ of WHO, in May 2003, just prior to the end of Brundtland's term as Director-General.

As I have described elsewhere, these legal developments may herald a "turning-point": a new era in international health cooperation and, perhaps, an important step towards a new international health law leadership role for WHO. ${ }^{55}$ The Organization's unprecedented consideration of the role of international law and institutions in promoting public health policies in tobacco control and other reaims of international health law concerns suggests a rethinking, reformulation and expansion of the organization's traditional scientific, technical approaches to public health.

The question that remains is whether or not the organizational changes initiated under Brundtland. a unique WHO head because of her unconventional background in international lawmaking and diplomacy as well as public health, reflect merely limited and inconsequential deviations from established procedures or key steps towards genuine adaptation or evolution WHO's conservative culture ${ }^{56}$ that will be sustained and fostered under WHO's new Director-General, Dr. Jong-wook Lee, and beyond. The process of change in international organizations is stimulated by a variety of factors external and internal to the institution, including organizational leadership. The heads of international organizations typically have considerable agenda-setting power and leadership change and institutional change frequently go hand in hand in international organizations. ${ }^{57}$

At the time of this writing Dr. Lee, a distinguished international . health practitioner who had been at WHO for a substantial number of years prior to his election as Director-General, has been in his new office for less than a year. It is, therefore, perhaps too soon to conclude whether or not his administration is committed to expanding WHO's leadership in international health law and whether or not new practices in this realm will be successfully institutionalized and integrated into the regular processes of the Organization. However, in a perhaps noteworthy early signal of Lee's support for international legal approaches for public health, on July 30, 2003 the Organization announced internal structural changes, including the creation of a new department incorporating ethics, trade, human rights and law. Prior to Lee's restructuring of the institution, WHO's work on these areas was conducted by discrete departments with limited connections to one another and substantial overlaps in mandates. The consolidation of these realms under a single department at WHO has the potential to significantly rationalize, coordinate, and advance WHO's work on international health law. More importantly, however, current conditions of increasing financial stringency at WHO, including increased reliance on the private-sector, may serve to limit or inhibit WHO's autonomy to promote the advancement of international health law. 
Ultimately, WHO's capacity to fulfill the leadership mandate described depends on political support from its member states, particularly the major powers who provide the majority of the Organization's budget. The willingness of governments to support this mandate will depend on factors external and internal to WHO. For example, consistency of legal regimes may not always be a priority, or even a goal, for states facing competing interests (principally from private-sector actors). Furthermore, the broadened mandate has important implications for WHO's budget and resources, which must be supported by states who may also face conflicting financial priorities. As described, WHO has been operating under the conditions of a declining budget in real terms, limiting its autonomy to effect decisions independent of its Member States and compounding pressure on the Organization to institute reforms and implement programmes that are responsive to the demands of key donors.

Governmental support of an expanded international health law mandate, in the near future, may also depend partly on assessment of the institution's existing strengths and past successes in contributing to the codification and administration of global health law. To this end, the 2003 WHO Framework Convention on Tobacco Control, the first treaty to be adopted under the auspices of the WHO in its fifty plus year history, may serve as a critical test of WHO's organizational and political capacity to provide leadership in future international health law efforts. The treaty will enter into force for state parties if and when it is ratified by forty states.

Much has been written about the effectiveness of the FCTC negotiation process in promoting national and international tobacco control. ${ }^{58}$ However, viewed as an international instrument, there are number of aspects of the FCTC that raise the concern that the treaty itself may have limited impact in promoting effective national and international action for tobacco control, including the elaboration of detailed protocol agreements, assuming it ultimately enters into force. The FCTC is modeled upon the framework convention-protocol approach, an approach to intemational lawmaking made popular in the realm of international environmental law. ${ }^{59}$ Although there is no single definition of a framework convention, such treaties tend to establish broad obligations and concrete institutions of global governance that provide a platform to promote negotiation and codification of detailed obligations in future protocol agreements. While the FCTC tends to establish broad obligations, the text is lacking many of the core institutional arrangements found at times in framework conventions, such as a prescribed annual or biannual meeting of the contracting parties, which serve as the bedrock for an ongoing international legislative enterprise

Despite some of the manifest limitations of the final text of the FCTC, governments' evaluations of WHO's role in the FCTC process are unlikely to depend on the substantive outcome of the FCTC whether the Convention and its proposed protocols are relatively effective or ineffective at promoting multilateral coordination to counter the tobacco pandemic or even if the FCTC ever enters into force. Intergovernmental organizations have important catalytic functions in treaty development, including the preparation of draft texts of the treaty. Ultimately, however, international organizations have limited capacity to influence the factors that encourage states to adopt, ratify, and implement effective commitments.

Rather, the willingness of states to use WHO as a platform, catalyst, and coordinator for international health law negotiations in the near future may depend on governments' final evaluations of WHO's effectiveness as a coordinator and manager of the FCTC negotiations and, potentially, the treaty regime. That is, governments are likely to collectively assess whether or not WHO provided the administrative coordination and public health expertise necessary to advance complex, multilateral negotiations in international health. Most importantly, perhaps, governments may evaluate WHO's capacity to address global health law matters in the near future on the basis of their collective assessment of whether or not WHO was able to serve as an honest broker for all states participating in the negotiation exercise. Some degree of tension between international organizations and their member states is commonplace in contemporary treaty negotiations. However, the states' collective judgment about the ability of an international organization to function as a neutral platform for all participating states is a critical element of the organization's ongoing political capacity to serve effectively as a center for international debate and codification.

In any assessment of WHO's performance as platform for the negotiations of the FCTC there are bound to be differences in judgment. Even so, perhaps many would agree that the institution's performance presents a mixed picture with some important successes and some major weaknesses. To this end, it is perhaps notable that in 2001, at the height of the FCTC negotiations, two new international legislative projects with potentially significant public health implications were initiated, the proposed convention banning the reproductive cloning of human beings and, as will be discussed further herein, a proposed Comprehensive and Integral International Convention on Protection and Promotion of the Rights and Dignity of Persons with Disabilities. Although WHO has the legal authority to serve as a platform for the negotiation of these proposed treaties, in both cases states chose an alternative forum. ${ }^{60}$ Perhaps notable as well, in the final text of the FCTC adopted in May 2003 Member States included a provision that granted WHO the status of interim treaty secretariat with the permanent secretariat to be designated after the treaty enters into force. For a variety of reasons WHO is ultimately likely to be awarded the permanent secretariat if the treaty enters into force. Nevertheless, the FCTC provision on WHO interim secretariat status is rather unusual since speciaiized agencies tend to be customarily granted permanent secretariat status without such an interim period in treaties negotiated solely under their auspices.

\section{Taking the Agenda Forward: Recommendations} for WHÓ Global Health Governance Leadership Global health problems pose important legal challenges for the international community. The increasingly globalized nature of public health problems calls for an unprecedented degree of international cooperation and leadership by the World Health Organization.

It is, of course, important that expectations for organizational action in this realm remain realistic. As described herein, WHO has highly limited experience and resources in international health lawmaking and coordination. In other realms of international concern, the capacity of international organizations in international lawmaking and mobilization has developed over a generation. Consequently, it may take years before WHO is able to build the requisite expertise to provide maximum leadership in international health law cooperation, mobilization, and codification. Further, as described above, effective coordination of international legal efforts cannot be guaranteed by WHO or by any other intergovernmental organization in a world of autonomous states. Recognizing these inherent limitations, an effort to rationalize the international health law enterprise is essential and should be advanced.

It should be recognized that concerns about the fragmented nature of the legal system and the absence of a coordinated approach to 
norm-creating process are not unique, of course, to international health or even international environmental law. Rather, concerns about conflicts among norms and conflicts of legal jurisdiction cut across a variety of international legal disciplines. A variety of commentators have urged that international organizations should forge more effective linkages to promote coherent norm development. To this end, increased attention is being paid to the various institutional and legal mechanisms that can be used to enhance inter-organizational collaboration, including, most notably, organizational leadership and oversight structures. This article cannot fully describe the strategies that WHO could use to promote rational management of international legal developments. However, scholarship in international environmental law suggests some important starting points. ${ }^{61}$ In particular, WHO can provide leadership and promote more coherent and effective development of international health law by endeavoring to serve as coordinator, catalyst and, where appropriate, platform for important international health agreements.

\section{Promoting Global Dialogue and Agenda Setting}

WHO can catalyze more effective and coordinated international health cooperation by promoting global awareness of international health law concerns and contributing to the "agenda-setting ${ }^{n 2}$ that is acutely needed in this reaim.

One of the major challenges in effective management of public health problems of international legal concern is mobilizing public awareness as well as national political commitment and action. Global health problems battle for political attention against other international issues. At the same time, public health remains low on the priority list for national action or international cooperation in many states.

WHO can establish a key role for itself in catalyzing international agreements and national action by, among other things, establishing a mechanism of educating and informing national policy-makers of critical public health issues ripe for international legal action. Among other things, WHO can institutionalize an open and inclusive process for identifying priority issues for international legal cooperation and promoting them among relevant constituencies. By identifying priorities for international legal action and coordinating relevant public health and legal information, WHO can serve a critical role and meet an essential need by building global dialogue and educating governments, other global health actors, including other intergovernmental organizations, and the public about global health issues of legal concern. Critical to the success of such a process is the establishment of a mechanism to extend the dialogue to national policymakers beyond ministries of health that form the traditional core of WHO's constituency. Effective coordination of such a process with other relevant intergovernmental organizations may serve to expand the network of national actors involved in the global heath law dialogue, promote national awareness and commitment, and contribute to the rationale development of the international legal regime.

In addition, constructing a more effective dialogue between states and the web of other global health actors will be a critical component of better collective management of international health law in the future. The rise of new global health actors, including civil society, religious groups, foundations, the private sector and broad international health coalitions has considerably complexified health governance and highlighted the limitations of the traditional state-centered focus of international law. Indeed, the complex network of governance structures that are burgeoning around the legal structures being established by the state-centered system indicates the need for an inclusive approach to engagement with new global health actors.

As a highly prominent international organization, WHO has the opportunity to play a pivotal role in building a dialogue among states and other health actors and in setting and launching the international health law agenda. Through these and other measures, WHO may promote global dialogue, build effective partnerships and stimulate more coordinated and, perhaps, more effective governmental and intergovernmental action.

\section{Monitoring International Health Law Dèvelopments and Promoting Coordinated Institutional Action}

WHO can also promote effective consideration, better collective management, and devclopment of international legal matters by monitoring and actively participating, where appropriate, in the increasing array of treaty efforts initiated in other forums that have important implications for global public health. For example, in December 2001, the General Assembly of the United Nations established an Ad Hoc Committee to consider proposals on a Comprehensive and Integral International Convention on Protection and Promotion of the Rights and Dignity of Persons with Disabilities. As a specialized agency of the United Nations system, WHO could contribute to this codification effort as an official observer to the negotiation sessions. However, the Organization did not contribute to the early sessions of the Ad Hoc Committee. WHO could make a significant contribution to this codification effort, and the development of international health law generally, by monitoring the legislative process and by informing and educating state delegations participating in negotiations about relevant public health and legal information.

Among other things, WHO could provide details of the global incidence of disabilities, and public health considerations involved in human rights issues of accommodation and access for persons with disabilities. Moreover, WHO may be able to broaden the dialogue and promote a comprehensive public health approach to disability by bringing forth information and stimulating global public debate on aspects of prevention, treatment and rehabilitation that may be ripe for national practice and, potentially, for inclusion in the text of the proposed treaty.

Further, as described above, WHO should incorporate other intergovernmental organizations with relevant mandates in the global dialogue on global health law priorities to promote more coordinated and rational development of the legal regime.

\section{Platform for Treaty Negotiations}

WHO can also effectively steer intergovernmental health cooperation by serving, where appropriate, as a platform for the codification and implementation of international legal agreements. The recent experience of biotechnology indicates that unless WHO plays a legislative role critical global public heaith issues may not be addressed in a timely and effective manner and may be subject to excessive institutional fragmentation and critical gaps. WHO is the only public internationai organization that brings together the institutional mandate, legal authority, and public heaith expertise for the codification of treaties that principally address global public health concerns.

Given the problems of legal jurisdiction raised by issue linkage and overlapping legal authority among various international organizations, a thorny question is which types of issues will beneft from codification under WHO's auspices. This needs to be decided on a caseby-case basis and there may always be differences in judgment. However, WHO is the appropriate institutional setting for the elaboration of legal standards encompassing issues, such as tobacco control, that overlap with other realms of international concern (such as human rights, trade, agriculture, customs, and the environment) but are at the heart of the public health mandate of WHO and are beyond the central mission of another public international organization.

\section{Conclusion}

International health law can make an important contribution to the framework for global cooperation and coordination on public health matters in an increasingly interdependent world. An essential component of global health governance in the twenty-first century is an effective and politically responsive institution to promote collective su- 
pervision as well as the coherent development of this rapidly evolving field. The extent to which WHO can and will be able to provide such leadership in international health law will have an important influence on the collective ability of intergovernmental organizations to promote effective global cooperation to advance global public health.

\section{References}

1. A.L. Taylor, "Global Governance, Intcrnational Law and WHO: Looking Towards the Future," Bulletin of the World Health Organization 80 (2002): $975-80$.

2. K.. Lee, "Shaping the Future of Global Health Cooperation; Where Can We Go From Hiere?" Lancet 351 (1998): 899-902.

3. K. Lee, "An Overview of Global Health and Environmental Risks," in L. Parsons and G. Lister, eds., Global Health: A Local Issue (London: The Nuffield Trust, 2000): 34-4.6.

4. F. Grad, "Public Health Law: Its Forms, Function, Future and Ethica Parameters," International Digest of Health Legislation 49 (1998): 19-40. A.L. Taylor, "Making the World Health Organization Work: A Legal Framework for Universal Access to the Conditions for Health, American Journal of Law and Medicine 18 (1992):301- 46.

5. GA Gellart, et. al., "The Obsolescence of Distinct Domestic and International Health Sectors," Joumal of Public Health Policy 10 (1989): 421-25.

6. R. Dodgson, K. Lee, and N. Drager, Global Health Governance: A Conceptual Review, (London: Center on Global Change \& Health. London School of Hygiene \& Tropical Medicine, 2002).

7. N. Drager and R. Beaglehole, "Globalization: Changing the Public Health Landscape," Bulletin of the World Health Ongarization 79 (2001): 803-09; D. Woodward, et. al., "Globalization and Health: A Framework for Analysis and Action, "Bulletin of the World Health Organization, 79 (2001): 875-81; A. Woodward, et. al., "Protecting Human Health in a Changing World: the Role of Social and Economic Development," Bulletin of the World Health Organization, (2000):1148-55; Dodgson, Lee, and Drager, szepra note 7

8. D. Nynar, "Towards Global Governance," in Governing Globalization (Oxford: Oxford University Press, 2002): 3-18

9. R. Adomo, "Biomedicine and International Human Rights Law: In Search of a Global Agenda," Bulletin of the World Health Organization 80 (2002): 959-63; G.J. Annas, L.B. Andrews, and R.M. Isasi, "Protecting the Endangered Human: Towards and International Treaty Prohibiting Cloning and Inheritable Alterations. American Journal of Law and Medicine 28 (2002):151-78; A.L.Taylor, "The Contribution of International Law to a Global Bioethic: The Proposed United Nations Convention Against the Reproductive Cloning of Human Beings," in J. Andreson, ed., Once in a Lifetime: Interdisciplinary Perspectives on Cloning and Genetic Technologies (Cambridge: Cambridge University Press [in press]).

10. P. Sands, "Sustainable Development: Treaty, Custom and the Cross-fertilization of International Law," in A. Boyle, and D. Freestone, eds.. Sustainable Development and International Law (Oxford: Oxford University Press, 1999):39-60.

II. J.E. Alvarez, ed., "Symposium: The Boundaries of the WTO," American Journal of International Law 96 (2002): I Taylor, infran note 23. 158

12. Commission on Human Security, Human Security Now: Protecting and Empowering People (2003), at <www.humansecurity-chs.org.>

13. A. Woodward, supra note II; G.H. Brundtland, Address to the World Business Council for Sustainable Development: our Common Future and Rio 10 years after: How far Have We Come and Where Should we be Going? November 4, 1999, Berlin, available at <http://wwwwho.int/directorgeneral/speeches/1999/english/19991104_berin.html.>

14. Taylor, supra note 1.

15. World Health Organization, WTO Agreements and Public Health, (Geneva: World Health Organization, 2002).

16. Sands, supra note 11.

17. H.D.C. Abbing, "Health, Human Rights, and Health Law: the Move Towards Internationalization, with a Special Emphasis on Europe" International Digest of Health Legislation, 49 (1998): 101-12; S. Gruskin and D. Tarantola, "Health and Human Rights," in Detels, supra note 4, at 311-57; A.L. Taylor et. al., "International Health Law Instruments: An Overview," in R. Detels, et. al., eds., Oxford Textbook of Public Health: The Scope of Public Health (Oxford: Oxford University Press, 2002): 359-86. 18. Gruskin and Tarantola, supra note 18

19. Id.

20. Grad, supra note 1.

21. Id.

22. Taylor, supra note 23.

23. L.C. Chen, T.G. Evans, and R.A. Cash, "Health as a Global Public Good" in I. Kaul, I. Grunberg, and M. Stern eds., Global Public Goods: International Cooperation in the 21st Century (London: United Nations Develop- ment Programme, 1999): 284-305; R. Smith, et. al. eds, Global Public Goods for Health: Health Economicand Public Health Perspectives (Oxford, Oxford University Press, 2002).

24. P.C. Szasz, "International Norm-Making," in E.B. Weiss, ed., Environmental Change and International Law (Tokyo: United Nations University Press, 1992): 340-84.

25. Taylor et, al., supra note 23

26. Chen, supra note 24 .

27. Id; K. Buse and G. Walt, "Global Public-Private Partnerships: Part 1 - a New Development in Health?" Bulletin of the World Health Organization 78 (2000): 549-61. M. R. Reich, ed. Public -Private Partnerships for Public Health (Cambridge: Harvard University Press, 2002).

28. Dodgson, Lee, arid Drager supra note 7

29. Chen, supra note 24 .

30. Dodgson, Lee, and Drager, supra note 7

31. G. Walt, "Globalisation of International Heal th." Lancet 351 (1998): 434-37. 32. D. Kapur, "Processes of Change in International Organizations," in Nynar, supra note 9 , at 334-55.

33. S. Charnovitz, "A World Environment Organization" Columbio Joumal of Environmental Law 27 (2002): 323-62; M.W. Doyle and R.I. Massey, -Intergovernmental Organizations and the Environment: Looking Towards the Future," in P.R. Chasek, ed., The Global Environment in the Twenty-First Century: Prospects for International Cooperation, (Tokyo: United Nations University Press, 2000) 41 I-26; P. Bimie and A. Boyle, In ternational Law and the Environment, (Oxford: Oxiord University Press 2002).

34. P.M. Haas, R.O. Keohane, and M.A. Levy, Institutions for the Earth: Sources of Effective International Environmental Protection, (Cambridge: MIT Press, 1993).

35. Charnovitz, supra note 34

36. A.L. Taylor. "Globalization and Biotechnology: UNESCO and an International Strategy to Advance Human Rights and Public Health," American Journal of Law and Medicine 25 (1999): 479-541.

37. See, e.g., United Nations Commission for Human Rights, Resolution 2001/71 on Human Rights and Bioethics, April 25, 2001

38. U.N. Wire, Discussion of U.N. Treaty on Human Cloning Delayed Two Years, November 6, 2003

39. Taylor, supra note 10

40. S.D.Murphy, "Biotechnology and International Law." Harvard Journal of International Law 42 (2001): 47-139; S. Pridan-Frank, "Human Genomics: A Challenge to the Rules of the Game of international Law," Columbia Journal of Transnational Law 40 (2001): 619-76.

4. Id.

42. J.P. Trachtman, "Institutional Linkage: Transcending "trade and..., American Journal of International Law 96 (2002): $77^{-93}$

43. Taylor, supra note 23; G.L. Burci and C.H. Vignes, "World Health Organization," in International Encyclopedia of Laws (Dordrecht: Kluwer [in press]).

44. Doyie and Massey, supra note 34.

45. Id.

46. P.C. Szasz, "IAEA Safeguards: Sanctions," in P.C. Szasz. Selected Essays on Understanding International Institutions and the Legislative Process (New York: Transnational Publishers 2001): 201-20.

47. Id.

48. Doyle and Massey, supra note 34

49. Taylor, supra note 5

50. Dodgson, Lee, and Drager, supra note 7.

51. Taylor, supra note 5 .

52. World Health Organization, "The-State-of-the-Art: A Human Rights Based Approach in WHO," Report to the Second Interagency Workshop on Implementing a Human Rights-based Approach in the Context of UN Reform. Stamford, USA. May 5-7, 2003

53. R. Roemer, J. Larvivier, and A. Taylor, "The Origins of the WHO Framework Convention on Tobacco Control," forthcoming in American Journal of Public Health.

54. A.L.Tayior and R. Roemer, "An International Strategy for Tobacco Control" (Geneva: World Health Organization: 1996) (WHO document WHO) PSA/96.6).

55. Taylor, supra note I.

56. Id.

57. Kapure, supra note 33

58. Roemer, LaRiviere, and Tayior, supra note 54

59. Taylor and Roemer, supra note 55.

60. G.L. Burci and C.H. Vignes, The World Health Organization (The Hague Kluwer Law International, 2004).

61. Doyle and Massey, supra note 34.

62.Id. 